\title{
Pengaruh Kesadaran WP, Pelayanan Fiskus, Sanksi Pajak, dan Tax Amnesty Pada Kepatuhan WPOP
}

\author{
I Gusti Putu Agung Darma Wicaksana ${ }^{1}$ \\ Ni Luh Supadmi \\ ${ }^{1,2}$ Fakultas Ekonomi dan Bisnis Universitas Udayana (Unud), Bali, Indonesia \\ e-mail: darmawicaksana29@gmail.com
}

\begin{abstract}
ABSTRAK
Penelitian ini bertujuan untuk mengetahui pengaruh kesadaran wajib pajak, pelayanan fiskus, sanksi pajak, dan tax amnesty pada kepatuhan wajib pajak orang pribadi di KPP Pratama Tabanan. Penelitian ini dilaksanakan di KPP Pratama Tabanan. Jumlah sampel yang diambil sebanyak 100 orang wajib pajak. Metode yang digunakan adalah nonprobability sampling, dengan teknik purposive sampling. Pengumpulan data dilakukan dengan penyebaran kuesioner dan observasi nonpartisipan. Data dianalisis dengan menggunakan analisis regresi linear berganda. Berdasarkan hasil penelitian menunjukkan bahwa kesadaran wajib pajak, pelayanan fiskus, sanksi pajak, dan tax amnesty berpengaruh positif pada kepatuhan wajib pajak orang pribadi di KPP Pratama Tabanan. Hasil penelitian menunjukkan bahwa kesadaran wajib pajak, pelayanan fiskus, sanksi pajak, serta pelaksanaan kebijakan tax amnesty dapat meningkatkan kepatuhan wajib pajak di KPP Pratama Tabanan.
\end{abstract}

Kata Kunci: Kesadaran wajib pajak, pelayanan fiskus, sanksi pajak, tax amnesty, kepatuhan wajib pajak

\begin{abstract}
This study aims to determine the effect of taxpayer awareness, tax authorities, tax sanctions, and tax amnesty on individual taxpayer compliance at the Tabanan Primary Tax Office. This research was conducted at the Tabanan Primary Tax Office. The number of samples taken is 100 taxpayers. The method used is nonprobability sampling, with a purposive sampling technique. Data collection is done by distributing questionnaires and nonparticipant observations. Data were analyzed using multiple linear regression analysis. Based on the results of the study showed that the awareness of taxpayers, tax authorities, tax sanctions, and tax amnesty had a positive effect on the compliance of individual taxpayers at Tabanan Primary Tax Office. The results showed that the awareness of taxpayers, tax authorities, tax sanctions, and the implementation of the tax amnesty policy could increase taxpayer compliance at the Tabanan Primary Tax Office.
\end{abstract}

Keywords: Awareness of the taxpayer, service tax authorities, tax penalties, tax amnesty, taxpayer compliance

\section{PENDAHULUAN}

Pembangunan nasional memiliki tujuan menciptakan keadilan dan kemakmuran bagi masyarakat. Pada masa pemerintahan Presiden Jokowi, pembangunan nasional difokuskan membangun infrastruktur penting, seperti jalan tol, pelabuhan, bandara, bendungan, dan infratruktur lainnya. Pemerintah sangat 
mengandalkan pendapatan dari pajak untuk merealisasikan pembangunan infrastruktur, disamping juga pendapatan dari sektor non pajak. Pendapatan sektor pajak merupakan pendapatan terbesar yang diterima oleh negara. Tabel 1 berikut menyajikan realisasi penerimaan negara Tahun 2013-2017.

Tabel 1.

Realisasi Penerimaan Negara Tahun 2013 - 2017

(TriliunanRupiah)

\begin{tabular}{lccl}
\hline Tahun & Penerimaan Pajak & Penerimaan Bukan Pajak & Total \\
\hline 2013 & $1.077,3$ & 354,8 & 1432,1 \\
2014 & $1.146,9$ & 398,6 & $1.545,5$ \\
2015 & $1.240,4$ & 255,6 & 1.496 \\
2016 & 1.539 .2 & 245.1 & $1.784,3$ \\
2017 & 1.495 .9 & 240.4 & $1.736,3$ \\
\hline Sumber: www.bps.go.id, 2018 & &
\end{tabular}

Berdasarkan Tabel 1, penerimaan pajak lebih besar dibandingkan penerimaan bukan pajak. Penerimaan negara dari sektor pajak tahun 2013-2017 juga meningkat setiap tahunnya. Keadaan tersebut membuktikan bahwa pajak merupakan penerimaan yang sangat penting bagi negara untuk pembangunan nasional (Alabede et al., 2011).

Melihat peranan pajak yang sangat penting bagi negara, maka dari itu Pemerintah berusaha meningkatkan penerimaan pajak dengan melakukan perluasan subjek dan objek pajak. Pemerintah juga memasang target penerimaan pajak untuk setiap Kantor Pelayanan Pajak Pratama di seluruh Indonesia, salah satunya di KPP Pratama Tabanan. Target penerimaan pajak di KPP Pratama Tabanan setiap tahunnya ditetapkan meningkat, namun penerimaan pajak lebih kecil jika dibandingkan dengan target yang ditetapkan. Tabel 2 berikut menyajikan target dan realisasi penerimaan pajak di KPP Pratama Tabanan 20132017. 
Tabel 2.

Target dan Realisasi Penerimaan Pajak di KPP Pratama Tabanan Tahun 2013 - 2017 (Rupiah)

\begin{tabular}{llll}
\hline TahunTarget & \multicolumn{1}{c}{ Realisasi } & Tingkat Realisasi & $(\%)$ \\
\hline 2013 & 302.027 .948 .013 & 260.665 .848 .280 & 86,3 \\
2014 & 316.572 .004 .000 & 273.122 .181 .492 & 86,3 \\
2015 & 410.762 .364 .999 & 310.175 .154 .821 & 75,5 \\
2016 & 475.007 .785 .999 & 373.180 .299 .659 & 78,6 \\
2017 & 449.117 .947 .999 & 353.006 .484 .041 & 78,6 \\
\hline
\end{tabular}

Sumber: KPP Pratama Tabanan, 2018

Berdasarkan Tabel 2, realisasi penerimaan pajak tahun anggaran 2013-2014 relatif tinggi, namun tahun 2015 mengalami penurunan sebelum akhirnya membaik di tahun 2016-2017.

Kepatuhan wajib pajak orang pribadi di KPP Pratama Tabanan dalam hal pelaporan SPT juga masih rendah. Tabel 3 berikut menyajikan kepatuhan pelaporan SPT orang pribadi di KPP Pratama Tabanan Tahun 2013-2017.

Tabel 3.

Tingkat Kepatuhan Wajib Pajak Orang Pribadi dalam Pelaporan SPT di KPP Pratama Tabanan Tahun 2013 - 2017

\begin{tabular}{lcccc}
\hline Tahun & WPOP & WPOP & $\begin{array}{c}\text { WPOP yang } \\
\text { menyampaikan SPT }(\%)\end{array}$ & Kepatuhan \\
& 84.689 & 60.541 & 42.351 & 69,95 \\
2013 & 92.196 & 67.825 & 37.703 & 55,59 \\
2014 & 100.169 & 75.621 & 45.849 & 60,63 \\
2015 & 107.973 & 83.243 & 42.922 & 51,56 \\
2016 & 116.865 & 92.030 & 41.833 & 45,46 \\
2017 & & &
\end{tabular}

Sumber: KPP Pratama Tabanan, 2018

Berdasarkan Tabel 3, diketahui tingkat pelaporan SPT cenderung mengalami penurunan dari tahun 2013-2017. Tahun 2017 tingkat kepatuhannya 45,46 persen dimana tingkat kepatuhan ini lebih rendah dari tingkat kepatuhan nasional sebesar 72 persen (Kompas.com, 2018). Meningkatkan kepatuhan wajib pajak adalah permasalahan yang harus diselesaikan pembuat kebijakan (Togler, 2005). 
Wajib pajak dikatakan patuh jika memiliki kemauan untuk menjalani kewajiban pajaknya sesuai peraturan perpajakan yang berlaku (James dan Clinton, 2004). Kepatuhan pajak merupakan keadaan dimana wajib pajak mengikuti peraturan dan regulasi pajak yang berlaku (Norasmila dan Azlan, 2014). KPP Pratama Tabanan sering melakukan sosialisasi kepada wajib pajak untuk lebih taat dalam mematuhi peraturan perpajakan yang berlaku, namun tetap saja ada wajib pajak kurang patuh. Ketidakpatuhan tejadi karena kesadaran wajib pajak dalam membayar pajak dan juga melaporkan SPT masih rendah. Wajib pajak juga belum paham cara pengisian SPT, hal ini tentu membuat wajib pajak enggan untuk melaporkan SPT.

Kesadaran merupakan keadaan dimana wajib pajak paham dan mengerti perihal pajak, serta mau melaksanakan kewajibannya untuk membayar pajak (Puri, 2014). Meningkatkan kesadaran akan pentingnya membayar pajak mendorong wajib pajak untuk aktif membayar pajak (Suryadi, 2006). Kesadaran wajib pajak dapat dikatakan sebagai sikap wajib pajak yang taat dan secara sukarela membayar pajaknya tepat waktu. Wajib pajak yang taat membayar pajak akan membuat roda pemerintahan berjalan lancar, hal ini akan mempercepat pembangunan nasional.

Berdasarkan penelitian Harefa (2013), yang dilakukan di KPP Pratama Jakarta Senen diketahui bahwa kesadaran wajib pajak memiliki pengaruh yang positif pada kepatuhan wajib pajak. Penelitian Puri (2014) dan Agustiningsih (2016) menunjukkan kesadaran wajib pajak memiliki pengaruh positif signifikan pada kepatuhan wajib pajak. Penelitian berbeda dihasilkan oleh Rorong dkk 
(2017) serta Suryadi (2006) yang menyatakan bahwa kesadaran wajib pajak tidak berpengaruh positif dan signifkan pada kepatuhan wajib pajak.

Pelayanan fiskus juga dapat meningkatkan kepatuhan wajib pajak. Wajib pajak bersedia membayar pajak dipengaruhi oleh pelayanan fiskus (Palda dan Hanousek, 2002). Fiskus diharapkan mampu memberikan pemahaman yang baik kepada masyarakat tentang aturan pajak yang ada, yang pada akhirnya akan meningkatkan kemauan wajib pajak membayar pajak (Puri, 2014). Pihak fiskus diharapkan memberikan pelayanan yang bagus kepada wajib pajak guna meningkatkan kesadaran wajib pajak untuk menciptakan kepatuhan wajib pajak dalam memenuhi kewajiban perpajakannya (Yudharista, 2014).

Penelitian Widyastuti (2015) di KPP Pratama Surakarta menunjukkan pelayanan yang baik dari fiskus berpengaruh positif pada kepatuhan wajib pajak. Penelitian Andriani Pratiwi dan Ery Setiawan (2014) yang dilakukan di Dinas Pendapatan Kota Denpasar juga menunjukkan bahwa pelayanan yang baik dari fiskus berpengaruh positif pada kepatuhan wajib pajak. Hasil berbeda didapatkan dari penelitian Sari (2017) dan Harefa (2013) yang menyatakan pelayanan fiskus tidak berpengaruh positif dan sinifikan pada kepatuhan wajib pajak.

Sanksi pajak merupakan salah satu faktor yang dapat meningkatkan kepatuhan wajib pajak. Sanksi pajak adalah kebijakan yang ampuh untuk mencegah timbulnya sikap tidak patuh dari wajib pajak (Ali, 2001). Sanksi pajak merupakan suatu aturan yang digunakan sebagai alat oleh petugas pajak agar wajib pajak tidak melanggar norma perpajakan (Mardiasmo, 2016:62). Sanksi pajak merupakan suatu peraturan perundangan perpajakan yang berisi sanksi- 
sanksi apabila lalai dalam melaksanakan kewajiban perpajakan. Sanksi pajak dibuat guna mengurangi perilaku pelanggaran hukum yang dilakukan oleh wajib pajak.

Penelitian Rahayu (2017), Krisna Dewi dan Lely Aryani Merkusiwati (2018), mendapatkan hasil dimana sanksi pajak memiliki pengaruh positif pada kepatuhan wajib pajak. Pada Penelitian Arum (2012) sanksi pajak juga memiliki pengaruh positif pada kepatuhan wajib pajak. Hasil berbeda didapatkan oleh Siti Masruroh dan Zulaikha (2013) di KPP Pratama Tegal, dimana sanksi pajak tidak memiliki pengaruh pada kepatuhan wajib pajak. Harefa (2013) juga mendapat hasil sanksi pajak tidak memiliki pengaruh positif pada kepatuhan wajib pajak.

Pemerintah juga terus melakukan berbagai upaya guna mampu menambah pendapatan negara dari sektor pajak, seperti kebijakantax amnesty. Tax Amnesty adalah upaya reformasi pajak dimana WP diberi kesempatan untuk melaporkan penghasilan yang sebenarnya tanpa dikenai sanksi. Reformasi pajak diharapkan mendorong peningkatan penerimaan pajak (Kanghua Zeng et al, 2013).

Tax Amnesty dilakukan dengan pengungkapan harta yang sebenarnya oleh wajib pajak, dimana pajak yang terutang sebelumnya akan dihapus serta tidak dikenai sanksi sebagaimana diatur dalam Undang-Undang Pengampunan Pajak Nomor 11 Tahun 2016. Tujuan tax amnesty berdasarkan pasal 2 Undang-undang Nomor 11 Tahun 2016 ada tiga. Pertama, mempercepat pertumbuhan ekonomi karena wajib pajak memindahkan hartanya dari luar negeri ke Indonesia. Kedua, mendorong terjadinya reformasi perpajakan di Indonesia agar lebih terintegrasi. Ketiga, dapat meningkatkan penerimaan sektor pajak. 
Tax Amnesty adalah kesempatan terbaik yang wajib digunakan oleh Wajib Pajak yang belum mencantumkan seluruh hartanya, hal ini karena kesempatan ini tidak datang dua kali. Pelaksanaan tax amnesty terakhir dilakukan 32 tahun yang lalu yaitu tahun 1984. Kebijakan tax amnesty setidaknya tidak akan diberikan lagi hingga beberapa puluh tahun kedepan.

Pemerintah melalui Dirjen Pajak aktif melakukan sosialisasi tentang program tax amnesty. Sosialisasi dilakukan melalui berbagai media, seperti media cetak, maupun media online. KPP Pratama Tabanan sendiri juga aktif melakukan sosialisasi tentang program tax amnesty ini, salah satunya dengan pemasangan banner tentang tax amnesty didepan KPP Pratama Tabanan. KPP Pratama Tabanan juga meningkatkan pelayanan agar wajib pajak terlayani dengan baik.

Berdasarkan data dari Kompas.com (2017), program tax amnesty berhasil mengungkap harta wajib pajak mencapai $\mathrm{Rp} 4.855$ triliun. Repatriasi aset mencapai Rp 147 triliun. Total penerimaan negara sebesar Rp 135 triliun, dengan jumlah peserta tax amnesty mencapai 956.000 wajib pajak. Pada KPP Pratama Tabanan sendiri terdapat 2.136 wajib pajak orang pribadi yang mengikuti tax amnesty.

Penelitian Suyanto dkk (2016) serta Ngadiman dan Daniel Huslin (2015) mendapatkan hasil tax amnesty memiliki pengaruh positif pada kepatuhan wajib pajak orang pribadi. Rahayu (2017) juga mendapatkan hasil tax amnesty memiliki pengaruh pada kepatuhan wajib pajak orang pribadi. Penelitian Sholichah (2018) dan Ipek (2012) mendapatkan hasil tax amnesty tidak berpengaruh pada kepatuhan wajib pajak. 
Penelitian ini menggunakan theory of planned behavior dan teori legitimasi. Munculnya suatu perilaku ditentukan oleh niat berperilaku yang dimiliki seseorang menurut Theory of planned behavior (Ajzen, 1991). Teori legitimasi merupakan keadaan dimana perusahaan memiliki nilai yang sejalan dengan sistem sosial yang ada (Ghozali dan Cariri, 2007:411). Legitimasi didapat ketika perusahaan memiliki nilai yang sama dengan sistem nilai sosial yang lebih besar (Gray et al, 1995). Legitimasi antara masyarakat dan perusahaan saling berkaitan (O’Donovan 2002). Legitimasi didapat jika ada kesamaan antara hasil dengan harapan masyarakat dari perusahaan (Deegan, 2002). Teori legitimasi menjadi landasan bagi perusahaan untuk memperhatikan harapan masyarakat (Suchman,1995).

Kesadaran merupakan hal yang penting agar seseorang melaksanakan kewajibannya dengan baik. Jika dikaitkan dengan theory of planned behavior pada faktor behavioral beliefs, maka teori ini tepat digunakan untuk menjelaskan perilaku wajib pajak dalam melaksanakan kewajiban perpajakannya. Ketika wajib pajak ingin membayar pajak, maka ia mempunyai keyakinan tentang manfaat dari pajak yang dibayarnya.

Teori legitimasi juga mendukung pernyataan dimana kesadaran wajib pajak berpengaruh pada kepatuhan wajib pajak. Wajib pajak mau membayar pajak berarti mematuhi sistem perpajakan yang berlaku. Penelitian Muliari dan Setiawan (2010) mendapatkan hasil dimana kesadaran wajib pajak memiliki pengaruh positif pada kepatuhan wajib pajak. Penelitian Rosyida (2018), serta Pattinaja dan Revi (2018) juga menemukan adanya pengaruh positif antara 
kesadaran wajib pajak dengan kepatuhan wajib pajak. Atas landasan teori serta hasil penelitian dimasa lalu, dapat dirumuskan hipotesis berikut:

$\mathrm{H}_{1}$ : Kesadaran Wajib Pajak berpengaruh pada Kepatuhan Wajib Pajak Orang Pribadi di KPP Pratama Tabanan.

Fiskus adalah petugas pajak yang bertugas untuk membantu wajib pajak. Berdasarkan Theory of Planned Behavior pada bagian normative beliefs dikatakan bahwa ketika hendak melakukan sesuatu seseorang biasanya mempunyai keyakinan dan motivasi untuk merealisasikan harapan orang lain. Petugas pajak yang memberi pelayanan dengan baik, diharapkan memberi motivasi kepada wajib pajak agar taat dalam peraturan perpajakan yang berlaku.

Penelitian Puri (2014) menyatakan pelayanan fiskus memiliki pengaruh positif terhadap kepatuhan wajib pajak. Fuadi dan Yenni (2013), serta Wilda (2015) juga menyatakan bahwa pelayanan fiskus memiliki pengaruh positif terhadap kepatuhan wajib pajak. Atas landasan teori serta penelitian dimasa lalu, dapat dirumuskan hipotesis berikut:

$\mathrm{H}_{2}$ : Pelayanan Fiskus berpengaruh pada Kepatuhan Wajib Pajak OrangPribadi di KPP Pratama Tabanan.

Sanksi pajak adalah jaminan bahwa peraturan perpajakan akandipatuhi oleh wajib pajak. Sanksi pajak terkait dengan control beliefs dalamTheory of Planned Behavior. Teori legitimasi juga mendukung sanksi pajak berpengaruh pada kepatuhan wajib pajak. Wajib pajak yang lalai dalam melaksanakan kewajiban pajaknya akan dikenakan sanksi perpajakan yang berlaku. 
Penelitian Arum (2012) menyebutkan sanksi pajak berpengaruh positif terhadap kepatuhan wajib pajak orang pribadi. Penelitian Esti (2012), serta Rahayu (2017) juga menyatakan bahwa sanksi pajak memiliki pengaruh positif pada kepatuhan wajib pajak. Atas landasan teori serta penelitian dimasa lalu, dapat dirumuskan hipotesis berikut:

$\mathrm{H}_{3}$ : Sanksi Pajak berpengaruh pada Kepatuhan Wajib Pajak Orang Pribadi di KPP Pratama Tabanan.

Kebijakan Tax Amnesty adalah kebijakan yang dikeluarkan oleh Pemerintah untuk meningkatkan penerimaan pajak negara. Tax amnesty berkaitan dengan ketiga faktor dalam Theory of Planned Behavior. Pada faktor behavioral beliefs, wajib pajak yakin bahwa kebijakan tax amnesty akan memberikan keuntungan, karena hutang pajak yang selama ini dimiliki akan dihapus. Pada faktor normative beliefs, Pemerintah sangat berharap masyarakat mau mengikuti tax amnesty karena akan meningkatkan pendapatan negara untuk pembangunan nasional. Pada faktor control beliefs, masyarakat diharapkan mengikuti tax amnesty, karena akan ada sanksi yang dikenakan apabila masyarakat tidak mengikutinya.

Teori legitimasi juga mendukung pengaruh tax amnesty pada kepatuhan wajib pajak. Tax amnesty merupakan kebijakan yang dikeluarkan oleh Pemerintah. Masyarakat diharapkan mengikuti tax amnesty agar sesuai dengan sistem perpajakan dimana masyarakat merupakan bagiannya.

Penelitian Jacques (2010) menunjukkan tax amnesty berpengaruh positif pada kepatuhan wajib pajak.Penelitian yang dilakukan oleh Ngadiman dan Daniel Huslin (2015) serta Junpath (2013) juga menyatakan bahwa kebijakan Tax Amnesty memiliki pengaruh positif pada kepatuhan wajib pajak orang pribadi. 
Atas landasan teori serta penelitian sebelumnya, maka dapat dirumuskan hipotesis berikut:

$\mathrm{H}_{4}$ : Kebijakan Tax Amnesty berpengaruh pada Kepatuhan Wajib Pajak Orang Pribadi di KPP Pratama Tabanan.

\section{METODE PENELITIAN}

Penelitian ini dilakukan dengan pendekatan kuantitatif yang berbentuk asosiatif. Penelitian ini dilaksanakan di KPP Pratama Tabanan. Alasan peneliti melakukan penelitian di KPP Pratama Tabanan karena tingkat kepatuhan wajib pajak orang pribadi cenderung turun dari tahun 2013-2017.

Obyek penelitian merupakan sasaran ilmiah guna memperoleh data tentang suatu hal yang bersifat objektif, valid, dan reliable (Sugiyono, 2017:38). Obyek pada penelitian ini adalah kepatuhan wajib pajak orang pribadi yang terdaftar di KPP Pratama Tabanan, yang dipengaruhi oleh kesadaran wajib pajak, pelayanan fiskus, pemahaman akan sanksi pajak, serta tax amnesty.

Populasi dalam penelitian ini adalah seluruh Wajib Pajak Orang Pribadi yang terdaftar dan merupakan wajib pajak efektif di KPP Pratama Tabanan, dimana jumlahnya pada tahun 2017 sebesar 92.030 orang. Sampel diambil menggunakan teknik purposive sampling. Sampel diambil dengan kriteria sebagai berikut: 1) WPOP terdaftar dan efektif di KPP Pratama Tabanan; 2) WPOP mengikuti tax amnesty. Jumlah sampel ditentukan dengan menggunakan rumus Slovin, dimana rumusnya sebagai berikut: 


$$
\mathrm{n}=\frac{\mathrm{N}}{\left(\mathrm{Ne}^{2}\right)+1}
$$

$$
\begin{aligned}
& \text { Dimana: } \\
& \mathrm{n}=\text { Jumlah sampel } \\
& \mathrm{N}=\text { Ukuran populasi } \\
& \mathrm{e}=\text { Batas kesalahan }(10 \%)
\end{aligned}
$$

Berdasarkan data, populasi berjumlah 92.030 orang, maka berdasarkan rumus slovin didapatkan sampel sebanyak:

$$
\mathrm{n}=\frac{92.030}{92.030(0,1)^{2}+1}=99,89
$$

Berdasarkan rumus slovin, didapatkan angka 99,89 yang peneliti bulatkan menjadi 100 sampel.

Data yang digunakan dalam penelitian ini ada dua, yaitu data kuantitatif dan data kualitatif. Data kuantitatif dalam penelitian ini berupa hasil pengisian kuesioner. Data kualitatif pada penelitian ini berupa daftar pertanyaan pada kuesioner. Sumber data dalam penelitian ini ada dua, yaitu sumber data primer dan data sekunder. Data primer diperoleh langsung dari sumber asli, data primer yang dimaksud disini adalah jawaban responden atas kuesioner yang disebarkan oleh peneliti di KPP Pratama Tabanan. Data sekunder diperoleh secara tidak langsung melalui media perantara, data sekunder yang digunakan dalam penelitian ini adalah jumlah peserta wajib pajak, jumlah pelapor SPT, dan jumlah target serta realisasi penerimaan pajak yang peneliti dapatkan dari petugas pajak di KPP Pratama Tabanan. 
Kuesioner dan observasi nonpartisipan adalah dua metode yang digunakan untuk mengumpulkan data pada penelitian ini. Metode kuesioner dilakukan dengan menyebarkan kuesioner kepada responden. Metode observasi nonpartisipan merupakan teknik pengumpulan data dimana peneliti hanya sebagai pengamat dan tidak terlibat didalamnya. Peneliti memperoleh data berupa sejarah, struktur, dan juga data jumlah wajib pajak di KPP Pratama Tabanan.

Analisis regresi linear berganda digunakan dalam penelitian ini, untuk mengetahui pengaruh kesadaran wajib pajak, pelayanan fiskus, sanksi pajak, dan tax amnesty pada kepatuhan wajib pajak orang pribadi. Model analisisnya sebagai berikut:

$$
\begin{aligned}
& \mathrm{Y}=\mathrm{a}+\mathrm{b}_{1} \mathrm{X}_{1}+\mathrm{b}_{2} \mathrm{X}_{2}+\mathrm{b}_{3} \mathrm{X}_{3}+\mathrm{b}_{4} \mathrm{X}_{4}+\mathrm{e}= \\
& \text { Keterangan: } \\
& \mathrm{Y}=\text { Kepatuhan wajib pajak } \\
& \text { a } \quad=\text { Konstanta } \\
& \mathrm{b}_{1} \quad=\text { Koefisien regresi kesadaran wajib pajak } \\
& \mathrm{b}_{2} \quad=\text { Koefisien regresi pelayanan fiskus } \\
& \mathrm{b}_{3} \quad=\text { Koefisien regresi sanksi pajak } \\
& \mathrm{b}_{4} \quad=\text { Koefisien regresi tax amnesty } \\
& \mathrm{X}_{1} \quad=\text { Kesadaran wajib pajak } \\
& \mathrm{X}_{2} \quad=\text { Pelayanan fiskus } \\
& \mathrm{X}_{3}=\text { Sanksi pajak } \\
& \mathrm{X}_{4} \quad=\text { Tax amnesty } \\
& \mathrm{e} \quad=\text { Eror }
\end{aligned}
$$

\section{HASIL DAN PEMBAHASAN}

Uji validitas dilakukan dengan menghitung nilai pearson correlation, dimana jika korelasi setiap faktornya positif dan nilainya lebih dari 0,3 maka instrumen yang digunakan valid. Tabel 4 menyajikan hasil uji validitas. 
Tabel 4.

Hasil Uji Validitas

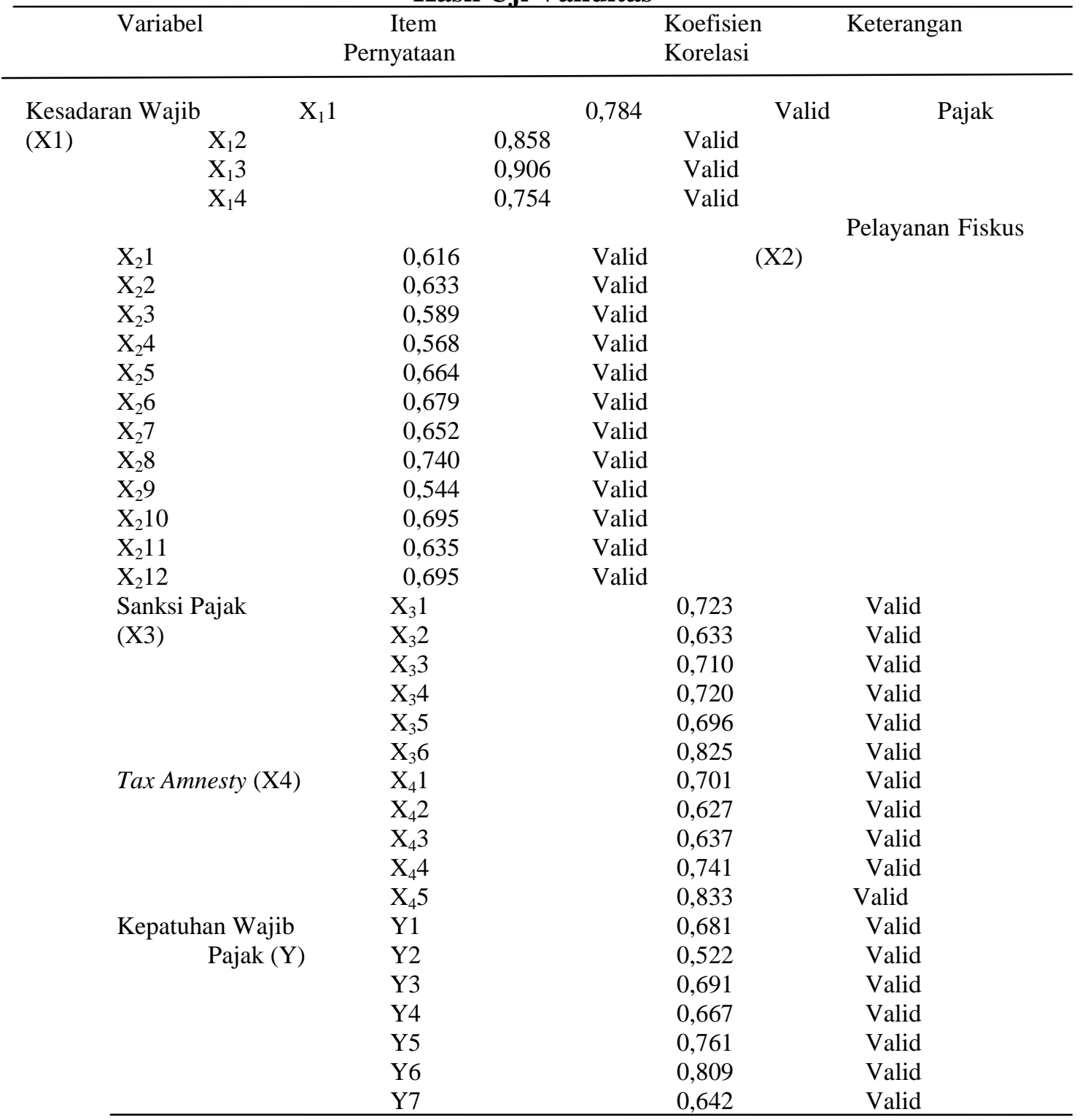

Sumber: Data diolah, 2018

Berdasarkan Tabel 4 dapat dilihat nilai Koefisien korelasi dari variabel kesadaran wajib pajak, pelayanan fiskus, sanksi pajak, tax amnesty, dan kepatuhan wajib pajak lebih besar dari 0,3. Pernyataan dalam kuesioner dapat dikatakan valid.

Kuesioner adalah indikator variabel diukur dengan uji reliabilitas (Sugiyono, 2017:125). Pengujian reliabilitas dilakukan dengan uji statistik 
cronbach alpha. Instrumen disebut reliabel apabila nilai cronbach alpha lebih besar dari 0,6. Hasil uji reliabilitas disajkan pada Tabel 5 berikut.

Tabel 5.

Hasil Uji Reliabilitas

\begin{tabular}{lcc}
\hline Variabel & Cronbach's Alpha & Keterangan \\
\hline Kesadaran Wajib Pajk (X1) & 0,833 & Reliabel \\
Pelayanan Fiskus (X2) & 0,865 & Reliabel \\
Sanksi Pajak (X3) & 0,802 & Reliabel \\
Tax Amnesty (X4) & 0,735 & Reliabel \\
Kepatuhan Wajib Pajk (Y) & 0,806 & Reliabel \\
\hline
\end{tabular}

Sumber: Data diolah, 2018

Berdasarkan Tabel 5 diketahui bahwa semua instrumen dalam penelitian ini mempunyai nilai cronbach's alpha lebih besar dari 0,6 sehingga pernyataan dalam kuesioner reliabel.

Statistik deskriptif digunakan untuk mendapatkan informasi tentang karakteristik variabel-variabel penelitian. Hasil statistik deskriptif dapat dilihat pada Tabel 6 berikut ini.

Tabel 6.

Hasil Uji Statistik Deskriptif

\begin{tabular}{lccccc}
\hline Variabel N & Minimum & Maximum & Mean & Std. Deviation \\
\hline Kesadaran & 100 & 8 & 16 & 12,05 & 1,755 \\
Wajib Pajak & & & & & \\
Pelayanan & 100 & 30 & 46 & 40,23 &, 739 \\
Fiskus & 100 & 14 & 24 & 19,79 &, 940 \\
Sanksi Pajak & 100 & 12 & 19 & 15,90 &, 521 \\
Tax Amnesty & & & & & \\
Kepatuhan & 100 & 17 & 27 & 22,79 &, 599 \\
Wajib Pajak & 100 & & & &
\end{tabular}

Berdasarkan Tabel 6 diketahui bahwa variabel kesadaran wajib pajak mempunyai nilai minimum 8 , nilai maximum 16 , nilai rata-rata 12,05 , dan standar deviasi sebesar 1,755. Variabel pelayanan fiskus mempunyai nilai minimum 30, nilai maximum 46, nilai rata-rata 40,23, dan standar deviasi sebesar 3,739. Variabel sanksi pajak mempunyai nilai minimum 14, nilai maximum 24, nilai 
rata-rata 19,79, dan standar deviasi sebesar 1,940. Variabel tax amnesty mempunyai nilai minimum 12 , nilai maximum 19 , nilai rata-rata 15,90 , dan standar deviasi sebesar 1,521. Variabel kepatuhan wajib pajak mempunyai nilai minimum 17 serta nilai maximum 27 , nilai rata-rata 22,79, dan standar deviasi sebesar 2,599.

Model regresi berganda yang baik adalah yang berdistribusi normal, untuk mengetahuinya dilakukan uji normalitas (Ghozali, 2013:160). Metode Kolmogorov-Smirnov Test digunakan untuk uji normalitas pada penelitian ini. Distribusi data disebut normal jika nilai signifikansi yang dihasilkan $>0,05$. Tabel 7 menampilkan hasil uji normalitas.

Tabel 7.

Hasil Uji Normalitas

\begin{tabular}{cc}
\hline & Unstandardizer Residual \\
\hline $\mathrm{N}$ & 100 \\
Asymp.Sig.(2-tailed) & 0,793 \\
\hline Sumber: Data diolah, 2018 &
\end{tabular}

Tabel 7 menampilkan hasil uji normalitas sebesar 0,793 dimana nilai ini diatas 0,05 . Hasil uji normalitas dengan model regresi menunjukkan bahwa nilai residual berdistribusi normal sehingga dikatakan layak untuk diuji.

Model regresi yang baik tidak terdapat korelasi yang tinggi antar variabel bebas, untuk mengetahuinya dilakukan uji multikolinearitas (Ghozali, 2013:105). Apabila terdapat korelasi yang tinggi antar variabel bebas, maka hubungan variabel bebas dengan variabel terikatdapat terganggu. Nilai tolerance $>0,1$ dan nilai VIF $<10$ untuk bebas dari masalah multikolinearitas. Tabel 8 menampilkan hasil uji multikolinearitas. 
Tabel 8.

Hasil Uji Multikolinearitas

\begin{tabular}{|c|c|c|c|c|}
\hline Variabel & Tolerance & & VIF & \\
\hline Kesadaran Wajib Pajak (X1) & 0,506 & & 1,976 & \\
\hline Pelayanan Fiskus (X2) & 0,599 & & 1,669 & Sanksi \\
\hline $\begin{array}{ll}\text { Pajak } & (\mathrm{X} 3) \\
& (\mathrm{X} 4)\end{array}$ & $\begin{array}{l}0,422 \\
0,578\end{array}$ & $\begin{array}{l}2,368 \\
1,731 \\
\end{array}$ & $\begin{array}{l}\text { Tax } \\
\text { Sumber: }\end{array}$ & $\begin{array}{r}\text { Amnesty } \\
\text { Data } \\
\end{array}$ \\
\hline
\end{tabular}

Berdasarkan Tabel 8 diketahui bahwa semua variabel bebas mempunyai nilai VIF dibawah 10 dan nilai tolerance diatas 0,10 . Hasil ini memperlihatkan bahwa multikolinearitas antar variabel bebas tidak ada dalam penelitian ini.

Ketidaksamaan varian dari residual pengamatan satu ke pengamatan yang lain dapat diketahui dengan uji heteroskedastisitas. Uji heteoskedastisitas memakai uji glejser dalam penelitian ini. Nilai signifikansi lebih besar dari 0,05 maka terbebas dari heteroskedastisitas. Hasil uji heteroskedastisitas dapat dilihat pada Tabel 9 berikut.

Tabel 9.

Hasil Uji Heteroskedastisitas

\begin{tabular}{lc}
\hline \multicolumn{1}{c}{ Variabel } & Signifikansi \\
\hline Kesadaran Wajib Pajak & 0,558 \\
Pelayanan Fiskus & 0,284 \\
Sanksi Pajak & 0,600 \\
Tax Amnesty & 0,147 \\
\hline Sumber: Data diolah, 2018 &
\end{tabular}

Tabel 9 memperlihatkan nilai signifikansi semua variabel bebas diatas 0,05 , hasil ini menunjukkan model regresi bebas dari heteroskedastisitas.

Analisis Regresi Linear Berganda digunakan untuk mengetahui besarnya pengaruh kesadaran wajib pajak, pelayanan fiskus, sanksi pajak, dan tax amnesty, pada kepatuhan wajib pajak di KPP Pratama Tabanan. Berdasarkan hasil olah data dengan SPSS, maka diperoleh hasil seperti pada Tabel 10 berikut. 
Tabel 10.

Hasil Analisis Regresi Linear Berganda

\begin{tabular}{|c|c|c|c|c|c|}
\hline \multirow[t]{2}{*}{ Model } & \multirow{2}{*}{$\begin{array}{c}\text { Unstandardized } \\
\text { Coefficients } \\
\text { B }\end{array}$} & \multirow[b]{2}{*}{$\begin{array}{c}\text { Std. } \\
\text { Error }\end{array}$} & \multirow{2}{*}{$\begin{array}{l}\text { Standardized } \\
\text { Coefficients } \\
\text { Beta }\end{array}$} & \multirow[t]{2}{*}{$\mathrm{t}$} & \multirow[t]{2}{*}{ Sig. } \\
\hline & & & & & \\
\hline (Constant) & $\begin{array}{l}-0,567 \\
\end{array}$ & 2,077 & & $-0,273$ & 0,786 \\
\hline $\mathrm{X} 1$ & 0,464 & 0,131 & 0,313 & 3,530 & 0,001 \\
\hline $\mathrm{X} 2$ & 0,185 & 0,057 & 0,266 & 3,261 & 0,002 \\
\hline $\mathrm{X} 3$ & 0,290 & 0,130 & 0,216 & 2,228 & 0,028 \\
\hline $\mathrm{X} 4$ & 0,289 & 0,142 & 0,169 & 2,038 & 0,044 \\
\hline \multicolumn{2}{|c|}{ Adjusted R Square } & \multicolumn{4}{|c|}{0,606} \\
\hline \multicolumn{2}{|c|}{ F Hitung } & \multicolumn{4}{|c|}{39,025} \\
\hline \multicolumn{2}{|l|}{ Sig. $F_{\text {hitung }}$} & \multicolumn{4}{|c|}{0,000} \\
\hline
\end{tabular}

Sumber: Data diolah, 2018

Berdasarkan Tabel 10 dapat disusun persamaan regresi sebagai berikut:

$$
Y=-0,567+0,464 X_{1}+0,185 X_{2}+0,290 X_{3}+0,289 X_{4}+e
$$

Nilai konstanta $-0,567$, hal ini berarti jika kesadaran wajib pajak (X1), pelayanan fiskus (X2), sanksi pajak (X3), dan tax amnesty (X4) bernilai nol, kepatuhan wajib pajak orang pribadi (Y) dalam membayar pajak menurun 0,567 satuan. Nilai koefisien b1 0,464 hal ini berarti jika nilai kesadaran wajib pajak (X1) mengalami kenaikan satu-satuan, maka kepatuhan wajib pajak orang pribadi (Y) mengalami kenaikan 0,464 satuan dengan asumsi variabel bebas lainnya sama dengan nol. Nilai koefisien b2 0,185 hal ini berarti jika nilai pelayanan fiskus (X2) mengalami kenaikan satu-satuan, maka kepatuhan wajib pajak orang pribadi (Y) mengalami kenaikan 0,185 satuan dengan asumsi variabel bebas lainnya sama dengan nol. Nilai koefisien b3 0,290 hal ini berarti jika nilai sanksi pajak (X3) mengalami kenaikan satu-satuan, maka kepatuhan wajib pajak orang pribadi (Y) mengalami kenaikan 0,290 satuan dengan asumsi variabel bebas lainnya sama dengan nol. Nilai koefisien b4 0,289 hal ini berarti jika nilai tax amnesty (X4) mengalami kenaikan satu-satuan, maka kepatuhan wajib pajak 
orang pribadi (Y) mengalami kenaikan 0,289 satuan dengan asumsi variabel bebas lainnya sama dengan nol.

Koefisien determinasi $\left(\mathrm{R}^{2}\right)$ berguna untuk mengetahui seberapa besar variabel bebas mampu menjelaskan variasi variabel terikat. Nilai Adjusted $R$ Square sebesar 0,606 atau 60,6 persen, jika dilihat dari Tabel 10. Hasil ini memiliki arti 60,6 persen variasi kepatuhan wajib pajak dipengaruhi oleh kesadaran wajib pajak, pelayanan fiskus, sanksi pajak, dan tax amnesty, sisanya 39,4 persen dipengaruhi faktor lainnya.

Uji $\mathrm{F}$ dilakukan guna mengetahui kemampuan variabel bebas untuk menerangkan variabel terikat. Berdasarkan Tabel 10 menunjukkan bahwa nilai signifikansi sebesar 0,000 lebih kecil dari 0,05. Berdasarkan hasil tersebut, bisa dikatakan variabel bebas mampu menjelaskan variabel terikat.

Uji t dilakukan untuk mengetahui seberapa besar variabel terikat dapat dijelaskan oleh masing - masing variabel bebas. Apabila nilai signifikansi variabel bebas < sama dengan 0,05 , bisa dibilang variabel terikat dipengaruhi secara individual oleh variabel bebas.

Berdasarkan Tabel 10 kesadaran wajib pajak mempunyai nilai signifikansi 0,001 dan t hitung 3,530, sehingga $\mathrm{H} 0$ ditolak dan H1 diterima. Pelayanan fiskus mempunyai nilai signifikansi 0,002 dan t hitung 3,261, sehingga $\mathrm{H} 0$ ditolak dan H2 diterima. Sanksi pajak mempunyai nilai signifikansi 0,028 serta t hitung 2,228, sehingga $\mathrm{H} 0$ ditolak dan $\mathrm{H} 3$ diterima. Tax amnesty mempunyai nilai signifikansi 0,044 dan thitung 2,038, sehingga H0 ditolak dan H4 diterima. 
Hipotesis pertama menyebutkan kesadaran wajib pajak memiliki pengaruh terhadap kepatuhan wajib pajak. Pengujian yang dilakukan membuktikan bahwa kesadaran wajib pajak memiliki pengaruh positif tehadap kepatuhan wajib pajak. Hasil ini mendukung theory of planned behavior pada faktor behavioral beliefs, terkait hubungan kesadaran wajib pajak pada kepatuhan wajib pajak. Apabila wajib pajak mempunyai keyakinan bahwa pajak digunakan untuk pembangunan nasional, maka kesadaran untuk membayar pajak akan meningkat yang pada akhirnya kepatuhan wajib pajak akan naik. Hasil ini juga mendukung teori legitimasi. Wajib pajak yang sadar untuk membayar pajak sejalan dengan sistem perpajakan yang ada, dimana wajib pajak merupakan bagian didalamnya. Hasil ini sama dengan penelitian Muliari dan Setiawan (2010), Rosyida (2018), serta Pattinaja dan Revi (2018) yang mengatakan bahwa kesadaran wajib pajak berpengaruh positif pada kepatuhan wajib pajak orang pribadi.

Hipotesis kedua menyebutkan pelayanan fiskus memiliki pengaruh pada kepatuhan wajib pajak orang pribadi di KPP Pratama Tabanan. Hasil pengujian memperlihatkan pelayanan fiskus memiliki pengaruh positif terhadap kepatuhan wajib pajak. Hasil ini mendukung theory of planned behavior pada faktor normative beliefs, terkait hubungan pelayanan fiskus pada kepatuhan wajib pajak. Hasil ini didukung oleh Puri (2014), Fuadi dan Yenni (2013), serta Wilda (2015) yang menyebutkan pelayanan fiskus memiliki pengaruh positif pada kepatuhan wajib pajak orang pribadi. 
Hipotesis ketiga menyebutkan sanksi pajak memiliki pengaruh pada kepatuhan wajib pajak orang pribadi di KPP Pratama Tabanan. Hasil pengujian memperlihatkan sanksi pajak memiliki pengaruh positif terhadap kepatuhan wajib pajak. Hasil ini mendukung theory of planned behavior pada faktor control beliefs, terkait hubungan sanksi pajak pada kepatuhan wajib pajak. Hasil ini mendukung teori legitimasi, dimana legitimasi memuat aturan-aturan yang yang harus dipatuhi oleh wajib pajak, dimana apabila aturan tersebut dilanggar akan ada sanksi yang dikenakan. Hasil ini sejalan dengan penelitian Arum (2012), Esti (2012), serta Rahayu (2017) yang mengatakan pelayanan fiskus memiliki pengaruh positif terhadap kepatuhan wajib pajak.

Hipotesis keempat menyebutkan tax amnesty memiliki pengaruh terhadap kepatuhan wajib pajak. Hasil pengujian memperlihatkan tax amnesty memiliki pengaruh positif terhadap kepatuhan wajib pajak. Hasil ini mendukung Theory of Planned Behavior untuk ketiga faktor terkait hubungan tax amnesty pada Kepatuhan Wajib Pajak. Pada faktor behavioral beliefs, wajib pajak meyakini bahwa kebijakan ini akan memberikan keuntungan, karena hutang pajak yang selama ini dimiliki akan dihapus. Pada faktor normative beliefs, Pemerintah sangat mengharapkan masyarakat mengikuti tax amnesty, dimana dana tebusan akan digunakan untuk pembangunan nasional. Pada faktor control beliefs, apabila wajib pajak tidak mengikuti tax amnesty maka akan dikenakan sanksi yang berat, berupa pengenaan denda 200 persen atas pajak penghasilan yang belum dibayar. Hasil ini juga mendukung teori legitimasi. Wajib pajak diharapkan mengikuti tax amnesty karena hal tersebut akan sejalan dengan sistem nilai perpajakan yang 
ada. Wajib pajak juga akan terhindar dari sanksi apabila telah mengikuti kebijakan tax amnesty. Hasil ini didukung oleh Suyanto dkk (2016), Ngadiman dan Daniel Huslin (2015), serta Rosyida (2018).

\section{SIMPULAN}

Kesadaran wajib pajak memiliki pengaruh positif terhadap kepatuhan wajib pajak di KPP Pratama Tabanan. Artinya, kesadaran wajib pajak yang tinggi akan meningkatkan kepatuhan wajib pajak. Pelayanan fiskus memiliki pengaruh positif pada kepatuhan wajib pajak di KPP Pratama Tabanan. Artinya, pelayanan yang baik dari fiskus akan meningkatkan kepatuhan wajib pajak. Sanksi pajak memiliki pengaruh positif pada kepatuhan wajib pajak di KPP Pratama Tabanan. Artinya, sanksi yang tegas akan meningkatkan kepatuhan wajib pajak. Kebijakan tax amnesty memiliki pengaruh positif pada kepatuhan wajib pajak di KPP Pratama Tabanan. Artinya, tax amnesty yang diselenggarakan dengan baik dan tegas akan meningkatkan kepatuhan wajib pajak.

Saran yang bisa diberikan bagi peneliti selanjutnya bisa melakukan penelitian dilokasi lain. Berdasarkan nilai Adjusted R-Square diketahui bahwa 60,6 persen variasi kepatuhan wajib pajak dipengaruhi oleh kesadaran wajib pajak, pelayanan fiskus, sanksi pajak, dan tax amnesty, 39,4 persen lagi dipengaruhi oleh faktor lainnya. Peneliti selanjutnya dapat menambahkan variabel lain seperti pengetahuan perpajakan. Saran bagi Pemerintah dalam hal ini Direktorat Jendral Pajak harus mampu menyampaikan sosialisasi yang baik kepada masyarakat agar tingkat kesadaran wajib pajak meningkat. Sosialisasi 
tentang kebijakan tax amnesty juga harus ditingkatkan, mengingat pentingnya program tersebut. Sanksi pajak juga harus ditegakkan secara tegas serta pelayanan yang baik kepada wajib pajak juga harus diberikan agar tingkat kepatuhan wajib pajak akan meningkat.

\section{REFERENSI}

Agustiningsih, Wulandari. 2016. Pengaruh Penerapan E-Filing, Tingkat Pemahaman Perpajakan dan Kesadaran Wajib Pajak Terhadap Kepatuhan Wajib Pajak di KPP Pratama Yogyakarta. Skripsi Sarjana Jurusan Akuntansi pada Fakultas Ekonomi dan Bisnis Universitas Negeri Yogyakarta.

Ajzen, Icek. 1991. The Theory of Planned Behavior: Organizational Behavior and Human Decision Processes. Vol. 50. Hlm. 179-211. University of Massachusetts at Amhest: Academic Press. Inc.

Alabede, James O, Zaimah Zainol Ariffin, dan Kamil Md Idris. 2011. Individual Taxpayers' Attitude and Compliance Behaviour in Nigeria: The Moderating Role of Financial Condition and Risk Preference. Journal of Accounting and Taxation, Vol 3(5), 91-104.

Ali. 2001. The Effects of Tax Rates And Enforcement Polices On Tax Payer Compliance: A study of Self-Employed Tax Payers. Antlantic economic journal, 29(2).

Andriani Pratiwi, I G. A. M. Agung Mas dan Putu Ery Setiawan. 2014. Pengaruh Kesadaran Wajib Pajak, Kualitas Pelayanan, Kondisi Keuangan Perusahaan,dan Persepsi Tentang Sanksi Perpajakn pada Kepatuhan Wajib Pajak Reklame di Dinas Pendapatan Kota Denpasar. E-Jurnal Akuntansi Universitas Udayana, 6 (1), hal.139 - 153.

Arum, Harjanti Puspa. 2012. Pengaruh Kesadaran Wajib Pajak, Pelayanan Fiskus, dan Sanksi Pajak terhadap Kepatuhan Wajib Pajak Orang Pribadi yang Melakukan Kegiatan Usaha dan Pekerjaan Bebas di KPP Pratama Cilacap. Skripsi Sarjana Fakultas Ekonomika dan Bisnis Universitas Diponegoro.

Badan Pusat Statistik. Realisasi Penerimaan Negara (Milyar Rupiah), Tahun 2007-2017. http://www.bps.go.id. Diakses 7 Juli 2018. 
Deegan, C. 2002. Introduction: The Legitimising Effect of Social and Environmental Disclosure - A Theoritical Foundation. Accounting, Auditing, and Accountability Journal, 5 (3): 282-311.

Donnal Putera, Andri. 2018. Dirjen Pajak Targetkan Kepatuhan Pelaporan SPT Naik Jadi 80 Persen. https://ekonomi.kompas.com/read/2018/03/08/163300926/dirjen-pajak targetkan kepatuhan-pelaporan-spt-naik-jadi-80-persen. Diakses 8 Januari 2019.1

Esti, Novia Wulandari Ni Putu. 2012. Pengaruh Persepsi Wajib Pajak Tentang Sanksi Perpajakan dan Kualitas Pelayanan pada Kepatuhan Wajib Pajak dalam Membayar Pajak Kendaraan Bermotor di Kantor Bersama Samsat Kota Denpasar. Skripsi Sarjana Jurusan Akuntansi pada Fakultas Ekonomi Universitas Udayana.

Fuadi, Arabella Oentari dan Yenni Mangoting. 2013. Pengaruh Kualitas PelayananPetugas Pajak, Sanksi Perpajakan dan Biaya Kepatuhan Pajak Terhadap Kepatuhan Wajib Pajak UMKM. Tax \& Accounting Review, 1 (1), hal. 35-42.

Ghozali, Imam. 2013. Aplikasi Analisis Multivariate dengan Program SPSS edisi 7.Semarang: Univesitas Diponegoro.

Ghozali, Imam dan Chariri. 2007. Teori Akuntansi. Semarang: Badan Penerbit Universitas Diponegoro.

Gray, et. al. 1995. Corporate Social and Environmental Reporting: A Review of Literature and a Longitudinal Study of UK Disclosure. Accounting, Audiitng, and Accountability Journal, Vol.8 No 2: 47-76.

Harefa, Maria Irene. 2013. Pengaruh Sikap Wajib Pajak, Pelaksanaan Sanksi Denda, Pelayanan Fiskus dan Kesadaran Perpajakan Terhadap Kepatuhan Wajib Pajak Orang Pribadi di KPP Pratama Jakarta Senen. Jurnal TEKUN, 4 (1), hal. 105-127.

Ipek, Selcuk, et al. 2012. Considerations of Taxpayers According to Situation of Benefiting From Tax Amnesty: An Empirical Research. International Journal of Business and Social Science. Vol. 3 No. 13; July 2012

Jacques, Malherbe. 2010. "Tax Amnesties in ghe 2009 Landscape". Dalam Inside Tax Magazine Edisi 34.

James, Simone \& Clinton Alley. 2004. Tax Compliance, Self Assessment and Tax Administration. Journal of Finance and Management in Public Services, Volume 2 Number 2, pp: 27-42. 
Junpath, Sachin. 2013. Multiple Tax Manesties and Compliance in South Africa. Durban University of Technology.

Kanghua Zeng, Shan Li, Qian Li. 2013. The Impact of Economic Growth and Tax Reform on Tax Revenue and Structure: Evidence from China Experience. Modern Economy, 4, 839-851.

Kantor Pelayanan Pajak Pratama Tabanan. 2018. Laporan Tahunan. Tabanan: KPP Pratama Tabanan.

Kisna Dewi, Luh Putu Santi dan Ni Ketut Lely Aryani Merkusiwati. 2018. Pengaruh Kesadaran Wajib Pajak, Sanksi Perpajakan, E-Filing, dan Tax Amnesty Terhadap Kepatuhan Pelaporan Wajib Pajak. E-Jurnal Akuntansi Universitas Udayana, 22 (2), hal.1626-1655.

Mardiasmo. 2016. Pepajakan Edisi Terbaru 2016. Yogyakarta: Andi.

Muliari, Ni Ketut \& Putu Ery Setiawan. 2010. Pengaruh Presepsi Tentang Sanksi Perpajakan dan Kesadaran Wajib Pajak pada Kepatuhan Pelaporan Wajib Pajak Orang Pribadi Di Kantor Pelayanan Pajak Pratama Denpasar Timur. Jurnal Ilmiah Akuntansi dan Bisnis, 6(1), hal. 1-23.

Ngadiman dan Daniel Huslin. 2015. Pengaruh Sunset Policy, Tax Amnesty, Dan Sanksi Pajak Terhadap Kepatuhan Wajib Pajak di Kantor Pelayanan Pajak Pratama Jakarta Kembangan. Jurnal Akuntansi, 19 (2), hal. 225-241.

Norasmila Awang and Azlan Amran. "Ethics and Tax Compliance" In Ethics, Governance and Corporate Crime: Challenges and Consequences. Published online: 08 Oct 2014; 105-113.

O'Donovan, 2002. Environmental Disclosure in the Annual Report: Extending the Applicability and Predictive Power of Legitimacy Theory. Accounting, Auditing and Accountability Journal, Vol.15, No.3, pp.344-371.

Palda, Filip and Jan Hanousek. 2002. Quality of Government Services and the Civic Duty to Pay Taxes in the Czech and Slovak Republics, and other Transition Countries.

Pattinaja, Elna Marsye dan Revi Wilhelmina Silooy. 2018. Pengaruh Sunset Policy, Tax Amnesty dan Kesadaran Wajib Pajak Terhadap Kepatuhan Wajib Pajak Pajak Orang Pribadi di KP2KP Masohi. Jurnal Manis, 2 (1), hal. 25-43. 
Puri, Kurnia Asrining. 2014. Pengaruh Kesadaran Wajib Pajak, Pelayanan Fiskus, Dan Sanksi Pajak Terhadap Kepatuhan Wajib Pajak Orang Pribadi Yang Melakukan KegiatanUsaha Dan Pekerjaan Bebas. Naskah Publikasi Fakultas Ekonomi dan Bisni Univesitas Muhammadiyah Surakarta.

Rahayu, Nurulita. 2017. Pengaruh Pengetahuan Perpajakan, Ketegasan Sanksi Pajak, Dan Tax Amnesty Terhadap Kepatuhan Wajib Pajak. Jurnal Akuntansi Dewantara, 1 (1), hal. 18-21.

Rorong, Elisabeth Nadia, Lintje Kalangi, dan Treesje Runtu. 2017. Pengaruh Kebijakan Tax Amnesty, Kesadaran Wajib Pajak dan Sanksi Pajak Terhadap Kepatuhan Wajib Pajak Orang Pribadi di KPP Pratama Manado. Jurnal Riset Akuntansi Going Concern, 12 (2), hal. 175-178.

Rosyida, Isnaini Anniswati. 2018. Pengaruh Pengetahuan Perpajakan, Kesadaran, dan Pengetahuan Tax Amnesty Terhadap Kepatuhan Wajib Pajak. Journal of Management and Accounting, 1 (1), hal. 29-43.

Sari, Viega Ayu Permata. 2017. Pengaruh Tax Amnesty, Pengetahuan Perpajakan, dan Pelayanan Fsikus Terhadap Kepatuhan Wajib Pajak. Jurnal ilmu dan riset akuntansi, 6(2), hal.747-752.

Sholichah, Siska Nur. 2018. Pengaruh Persepsi Wajib Pajak Tentang Kebijakan Tax Amnesty, Motivasi Membayar Pajak, Self Assessment, Tingkat Pendapatan dan Kualitas Pelayanan Terhadap Kepatuhan Wajib Pajak Orang Pribadi diKPP Pratama Karanganyar. Skipsi Sarjana Jurusan Akuntansi pada Fakultas Ekonomi dan Bisnis Universitas Muhammadiyah Surakarta.

Siti Masruroh dan Zulaikha. 2013. Pengaruh Kemanfaatan NPWP, Pemahaman Wajib Pajak, Kualitas Pelayanan, Sanksi Pajak Terhadap Kepatuhan Wajib Pajak Orang Pribadi di Kabupaten Tegal. Junal Akuntansi UNDIP, 2 (4), hal $2-20$.

Suchman, Mark C. 1995. Managing Legitimacy: Strategic and Institutional Approaches. The Academy of Management Review, Vol. 20. No.3, 1995

Sugiyono. 2017. Metode Penelitian Kuantitatif, Kualitatif Dan R\&D. Bandung: Alfabeta.

Suryadi. 2006. Model Hubungan Kausal Kesadaran, Pelayanan, Kepatuhan Wajib Pajak dan Pengaruhnya Terhadap Kinerja Penerimaan Pajak Suatu Survei di Wilayah Jawa Timur. Jurnal Keuangan Publik, 4 (1), hal. 105 - 121. 
Suryowati, Estu. 2017. Apakah Tujuan Program "Tax Amnesty” Tercapai ?. https://ekonomi.kompas.com/read/2017/04/04/213825226/apakah.tujuan.po ram.tax.amnesty.tercapai. Diakses 9 September 2018.

Suyanto, Pasca Putri Lopian Ayu Intansari, dan Supeni Endahjati. 2016. Tax Amnesty. Jurnal Akuntansi, 4 (2), hal. 9-22.

Togler, B. 2005. Direct Democracy and Tax Morale. European Journal of Political Economy, Vol 21(3), h:525-531.

Undang - undang Republik Indonesia Nomor 11 Tahun 2016 Pengampunan Pajak. 1 Juli 2016. Lembaran Negara Republik Indonesia Tahun 2016 Nomor 131. Jakarta.

Widyastuti, Ella. 2015. Pengaruh Tingkat Pemahaman Wajib Pajak, Kualitas Pelayanan Fiskus, Sanksi Perpajakan, dan Lingkungan Wajib Pajak Terhadap Tingkat Kepatuhan Wajb Pajak Orang Pribadi di KPP Pratama Surakarta. Naskah Publikasi Fakultas Ekonomi dan Bisnis Univesitas Muhammadiyah Surakarta.

Wilda, Fitri. 2015. Pengaruh Kesadaran Wajib Pajak, Pelayanan Fsisku dan Sanksi Pajak Terhadap Kepatuhan WPOP yang Melakukan Kegiatan Usaha dan Pekerjaan Bebas di Kota Padang. Skripsi Sarjana Jurusan Akuntansi pada Fakultas Ekonomi Univesitas Negeri Padang.

Yudharista, K. 2014. Pengaruh Kesadaran Wajib Pajak, Pelayanan Fiskus, Sanksi Pajak, Pengetahuan dan Pemahaman Perpajakan Terhadap Kepatuhan Wajib Pajak Orang Pribadi Yang Melakukan Kegiatan Usaha dan Pekerjaan Bebas di KPP Pratama Tulungagung. Skripsi Sarjana Jurusan Akuntansi pada Fakultas Ekonomi dan Bisnis Universitas Airlangga. 